\title{
MAHAMAT-SALEH HAROUN: DE LA GONFRONTAGIÓN A LA COMPETICIÓN
}

\author{
Fernando González García
}

Universidad de Salamanca

En este artículo trataremos, a través del estudio de los largometrajes y declaraciones de Mahamat-Saleh Haroun, de acercarnos a las circunstancias que impulsan un cine africano hecho desde la diáspora y su distinta relación con las tradiciones, con la propia historia del cine africano, y con los festivales internacionales. Trataremos también de profundizar en las estrategias narrativas de Haroun, sobre todo su particular forma de puesta en abismo, que propone al espectador una nueva mirada sobre África ${ }^{1}$.

Con ocasión de la presentación de Hyènes en Cannes, en 1992, seleccionada para la sección competitiva y nominada a la Palma de Oro, Djibril Diop Mambety decía en una entrevista que él no estaba allí en competición, sino en confrontación (Servais, Diop, Tapsoba, 1992: 2-6). Poco más añadía en aquella entrevista en este sentido. Sin embargo, vuelve a hablar de confrontación en otro lugar:

Hay que olvidar Cannes y todo lo que está en competición. Hay que amar la confrontación. Se trate de mi película o de la de otro. Es inútil entrar en ese juego. Tenemos cosas más urgentes que hacer. Más allá de los medios técnicos, estamos lejos de ser pobres. Continuemos valorando el cine como la máscara o la palabra que nos pertenecen (Batumike, 1992).

En 2010, Un homme qui crie, de Mahamat-Saleh Haroun consigue el Premio del Jurado en el mismo festival, trece años después de que Souleymane Cissé lo lograra por primera vez con Yeleen en 1987 y sin que, desde 1997, hubiera competido por la Palma de Oro en el Festival ninguna película subsahariana:

No me siento orgulloso. Estoy contento por el Chad, feliz por África. Pero también triste, ya que mi presencia aquí revela la invisibilidad del cine africano. De todas maneras, estoy

1 Este artículo se inscribe en el proyecto de investigación FFI2008-02810/FILO dirigido por José Antonio Pérez Bowie y titulado: «Transcescritura, transmedialidad y transficiconalidad. Relaciones entre literatura, cine y nuevos medios (1980-2010)». 
encantado por traer la palabra africana hasta Cannes, que es la Meca del cine (Souvannavong, 2010).

Entre las palabras de Mambety y las de Haroun hay una diferencia de matiz en la que conviene detenerse un momento. Para Mambety, debe haber confrontación cultural, siempre y cuando las obras estén a la altura de las de los competidores, y debe haber, finalmente, una toma de distancia de África con respecto a Europa. Interrogado por Ukadike sobre la posibilidad de hacer otra coproducción con Europa, Mambety respondió: «No quiero hablar de Europa. Hablemos de hacer películas en África. Europa no es importante para mí. El problema no es de dónde viene el dinero para hacer una película» (Ukadike, 1999).

Mambety, senegalés nacido en 1945, habla desde la experiencia del colonialismo, del neocolonialismo ora violento, ora disfrazado de paternalismo; Haroun, chadiano nacido en 1961, lo hace desde su experiencia como exiliado de un país que vive sumido en guerras civiles desde hace décadas, y que para hacer cine tiene que vivir fuera de África. La importancia, para Haroun, de estar en competición en Cannes, radica en la necesidad de hacer visible África de nuevo, de llevarla al centro de esa visibilidad que Cannes simboliza. Mambety pertenece a la primera generación de cineastas africanos, los que tras las independencias intentaron recuperar la propia imagen que les arrebató el colonizador, los que lucharon por un cine panafricano, por crear instituciones y políticas que permitieran la producción y circulación de películas africanas en África. Haroun a la de los nacidos tras la descolonización, cuyos miembros viven en un altísimo porcentaje en el exilio, hijos del neocolonialismo, de la guerra fría, de la deuda externa y del fracaso político no sólo de la construcción africana, sino en algunos casos incluso de las propias naciones. Esta generación es consciente de ese pasado tan reciente, de la estructura neocolonial de la producción y la distribución cinematográficas que les impidieron ver en su infancia y juventud cine africano -Mambety, Sembène, Med Hondo, Cissé entre tantos otros-, mientras las salas se inundaban de westerns, películas de acción o producciones indias. Con el añadido de que en la actualidad aquellas salas cierran para convertirse en almacenes, comercios o iglesias.

En lo que atañe al ámbito específico del cine en la actualidad, Haroun es claro cuando dice que se siente optimista respecto a la posibilidad de que en breve tiempo se den a conocer cinco o seis grandes realizadores, pero que no puede hablarse de cine africano, porque sólo hay — cuando las hay_ políticas cinematográficas locales:

Ese es otro problema con el que tenemos que luchar. No parece posible mientras que tantos de nosotros estemos exiliados en Europa. No es fácil involucrarse en las políticas locales o nacionales desde aquí. Ese es un gran problema (Scott, 2003: 91).

Los autores de esta generación, una de las mejor preparadas del mundo, según Roy Armes, que a sus estudios de cine en escuelas europeas y en algunos casos americanas, unen otras cualificaciones académicas, comparten muchos otros rasgos comunes en los que no me detendré (véase Armes, 2006: 143-157 y Barlet: 2000), salvo en tres: tener una base de producción en Europa, un fuerte sentido de solidaridad y un claro pragmatismo.

Pero estos cineastas africanos con base en París tienen una ventaja de la que se carece en otros exilios: su decisión de reflejar cinematográficamente la vida en los países en los 
que nacieron encuentra un apoyo precisamente en el deseo de los gobiernos franceses de mantener lazos culturales con todas sus antiguas colonias africanas. Su problema es menos el exilio que la potencial integración y la pérdida de la identidad africana (Armes, 2006: 146).

Ante la práctica imposibilidad de encontrar soporte productivo para realizar una película netamente africana, estos autores no rechazan la financiación europea, principalmente francesa, pero practican la colaboración y se agrupan en organizaciones dedicadas a defender sus intereses y a promover sus obras. Entre ellas, está la Guilde Africaine des réalisateurs et producteurs, iniciada en 1997, entre otros, por Mahamat-Saleh Haroun con el fin de mejorar las condiciones de producción ${ }^{2}$ y de visibilidad del cine africano ${ }^{3}$ :

Agrupados mayoritariamente en la Guilde africaine des réalisateurs et producteurs, estos jóvenes cineastas de la diáspora buscan una renovación. Rechazan la cultura del margen, luchan contra una cierta representación de África surgida del cine colonial, afirman su africanismo, pero en una cultura de la errancia, del nomadismo; lejos de fijaciones identitarias buscan un lenguaje cinematográfico apropiado para tratar los problemas urgentes de África, desarrollando entre ellos solidaridades que contrastan con el individualismo de sus mayores (Barlet, 2002).

\section{ESCRITURA Y TRADICIÓN EN MAHAMAT-SALEH HAROUN. Bye Bye Africa.}

El mío es un cine post-africano. Los que, en el cine africano, son aspectos esenciales, puestos en primer plano, yo los coloco en un segundo, los rechazo. Por ejemplo el concepto de tradición, porque para mí la cultura es lo que cuenta, y cultura y tradición no son lo mismo. (...) La tradición se puede modificar con el tiempo y en contacto con las cosas, mientras que la cultura es más sólida, es una visión del mundo, una filosofía de la vida que te da fuerza para seguir adelante. No quiero permanecer en el folklore. Soy un cineasta africano, pero no me reconozco en esa idea de cine africano que han construido la crítica e incluso los propios cineastas. La utopía que está en mi película es también la de mi idea de cine: poner en escena la propia problemática a través de la ficción, a través de la creación de un nuevo imaginario (De Franceschi, 2007).

Hay en las declaraciones de Mahamat-Saleh Haroun, hechas poco después del estreno de Daratt, película con la que triunfó en Venecia, una toma de distancia con respecto al cine

2 «Ante la mundialización, al cine holywoodiense dominante, queda muy poco sitio para las imágenes africanas. Y cuando las televisiones, como TV5, CF1 ○ Canal Horizon entran en liza, es para rematarnos, comprando nuestras películas a precios que desafían el mayor saldo. Sólo agrupándonos y proponiendo un baremo tarifario mínimo a todas las cadenas especializadas en África veremos respetado nuestro trabajo. Ante todo, el respeto a nuestro trabajo». La Guilde: «Pour un noveau cinéma africain», en Ruelle, 2005: 270.

3 «Estamos ante taquillas que nos ven a todos de la misma manera, como a pobres cineastas a los que ayudar. Pero, si hay algo que salvar, no es un 'cine africano' que por otra parte no existe, sino visiones de África por diferentes autores africanos. Si falta visión, nuestro horizonte será únicamente el de Fespaco, y no saldremos nunca de él, y nuestro cine estará cada vez más marginalizado, porque, saliendo de aquí, caminará de festival en festival 'étnico', los 'festivales de cine africano'. Se nace marginal y se termina marginal. Ningún cineasta que se respete sueña con eso» (Barlet, 2011). 
africano de las generaciones anteriores que quizás haya que relacionar con un debate que arranca de algún tiempo atrás. En 1997, Olivier Barlet publicaba un artículo en el que se hacía eco de un cambio de opinión de la crítica francesa acerca del cine africano de entonces. $\mathrm{Si}$ desde el premio de Cissé en Cannes con Yeleen y el éxito de Idrissa Ouedraogo con Tilaï, el público y la crítica occidentales elogiaron un cine centrado en la época precolonial o en el campo, a finales de los noventa arremeten contra él considerándolo naïf y alejado de la realidad, creando los conceptos despectivos de «film de brousse», o «film calebasse». Según Barlet, tanto el éxito primero como la reacción posterior parten de la misma falta de comprensión de las obras, considerándolas hermosas o infantiles sin saber realmente qué es lo que proponen y desconociendo profundamente la evolución de esta cinematografía: «Inocencia, género, la mirada occidental encierra las películas africanas en criterios reductores, negándoles su estética propia» (Barlet, 1997).

Era frecuente encontrar en las obras de ese período una preocupación profunda por la relación entre las tradiciones y la actualidad, entre el pasado precolonial y los problemas políticos y sociales actuales de África. Como hemos dicho en otro lugar (González García, 2010: 209-238), desde los años ochenta se produjo un nuevo interés por la tradición en general y por los relatos transmitidos por vía oral en particular, que tenía que ver con interrogarse acerca del pasado para afrontar los retos del presente. Formalmente, se trataba también de utilizar estructuras provenientes de la tradición oral y de formas de representación populares, para crear artefactos culturales mestizos, que pudieran ser sentidos como propios por el público africano, y como un hecho diferencial por los públicos internacionales. Esta tendencia no se oponía, sino que complementaba la «vía realista» impulsada por Sembène desde el inicio de las cinematografías africanas. A mediados de los noventa se producía entonces una situación muy inestable; los productos africanos parecían estar dirigidos a un doble público: el occidental, a través de los festivales, y el africano. Con un problema añadido: el público africano no existe, porque no puede ver las obras que teóricamente tienen en él su justificación última.

La generación de Mahamat-Saleh Haroun reacciona ante esta situación de atasco, de guetización de lo africano como género en los festivales internacionales a donde ya casi no acude, y de enclaustramiento en festivales específicos, mientras que el público africano sigue sin ver su propio cine, de una manera radical, negando el concepto de mestizaje y proponiendo el de nomadismo, poniendo en un segundo plano el problema de la tradición, y recuperando, muy transformada, la vía realista. Muy transformada porque tiene que ver con ella sólo el hecho de que lo que urge es hablar de la actualidad, ya que las soluciones narrativas son muy distintas.

Según Mahamat-Saleh Haroun, Bye, bye Africa es una película hecha desde la urgencia en la que quiso hablar de muchas cosas, unas encerradas dentro de otras, como en una muñeca rusa. Estoy utilizando declaraciones posteriores realizadas por el director y, al mismo tiempo las del personaje de Haroun, interpretado por él mismo en esta película en la que, sólo con mucho esfuerzo, se puede hacer el intento de separar lo que tiene de ficción y de documental. Sin embargo, interesa señalar algo antes de pasar adelante. Si la película provoca en el espectador una tensión derivada de la necesidad de saber dónde situar los límites entre el nivel documental y el ficcional, también es cierto que está atravesada y constituida a partir de otras tensiones, como las que se dan entre la realidad y el deseo, la derivada del exilio, y la que se da entre la actualidad y la tradición. 
Empezaré por esta última, para enlazar con el apartado anterior. Hacia el final de la película, vemos por primera vez el personaje de la abuela del protagonista, filmada como a escondidas cuando camina por el patio de la casa: el Haroun de la ficción reconoce que fue ella quien, con la voz dulce con la que le hablaba de niño, le enseñó a contar historias. En una entrevista, Mahamat-Saleh Haroun explica que ella es su auténtica abuela, sobre quien hubiera querido hacer una película; y dice que en Bye, bye, Africa quiso construir el argumento siguiendo el esquema de la narración oral africana.

El guión tiene una estructura, pero yo buscaba una historia relatada al estilo de la tradición oral... contando los segundos antes de cambiar de dirección. No es la manera convencional de escribir un guión, pero es lo que yo quería (Scott, 2003: 90).

Olivier Barlet va aún más allá que el mismo Haroun. En un artículo de 2000, no duda en utilizar Bye, bye África como paradigma del nuevo cine africano hecho desde la diáspora.

Más aún, una película como Bye bye Africa reagrupa una multitud de rasgos característicos de la tradición oral: modos de aproximarse a lo narrado que connotan la incertidumbre buscada, las precisiones y digresiones como paréntesis que aclaran el relato, las llamadas al espectador mediante rostros que miran a cámara, el sostenimiento de la ilusión de una doble mirada, con la cámara de video que marca la presencia de un público... Aparte de llamadas a la participación de los espectadores constantemente solicitados por el narrador (Barlet, 2000: 125).

El primer largometraje de Haroun no rechaza, pues, la tradición. Sin embargo, y a diferencia de los autores de la generación precedente, no llama la atención sobre ella, sino que, como él mismo decía, la coloca en un segundo plano. Resulta significativo que el personaje del director en la película no diga nunca nada parecido a lo que manifestó Haroun en la entrevista citada, sino que hable de estructurar la película que quiere hacer como una muñeca rusa.

Bye, bye Africa trata acerca de un director de cine que vuelve desde Francia al Chad natal cuando le comunican que su madre ha muerto. Además del dolor, llevará consigo una cámara digital y un guión. Al verle grabando todo lo que le rodea, su padre le dice que él hace películas para los blancos, «no para nosotros», que hubiera debido estudiar algo útil -si al menos hubiera sido médico, habría podido hacer algo por su madre-, y que lleva mucho tiempo fuera, de manera que quizá algún día decida quedarse allí, y entonces notará que algo se ha roto dentro de él mismo. Sólo mostrando a su padre películas caseras en las que aparece la madre joven, rodadas por un amigo de la familia le convencerá, usando palabras de Godard, de que el cine sirve para crear memoria. El padre le da su bendición, pidiendo a Dios que le ayude.

La aquiescencia del padre, todavía al inicio de la película, parece programática. Sin embargo, no se trata ya de recuperar la memoria histórica, sino de un interrogarse constantemente, desde el ámbito cerrado del cine, acerca de qué se puede hacer, como cineasta, en un país donde las salas han cerrado, donde la cultura está mediatizada por una situación de guerra interminable. De lo que se trata es de crear una nueva memoria. Pero ésta no puede ya partir de una base ideológica, ni desde la afirmación de una diferencia radical. Según Barlet, 
esta generación escapa del dilema de la diferencia poniendo en juego lo íntimo, inseparablemente del devenir de la comunidad:

En esto, prosiguen el camino trazado por sus antecesores. Esta voluntad de inscribir su reflexión íntima en lo real de la memoria de su pueblo les permite, como escribía Gilles Deleuze, franquear «la frontera que separaría sus asuntos privados de la política», y «producir enunciados colectivos» (Barlet, 2000: 119).

Sin embargo, y a diferencia de sus antecesores, la reflexión íntima no se subordina a lo ideológico: "se trata sobre todo de testimoniar las tensiones que siente el cineasta tanto en su situación de exiliado como en lo que percibe de África» (Barlet, 2000: 129)4.

Como Abderrahmane Sissako en La vie sur terre, Mahamat-Saleh Haroun interpreta al protagonista de Bye bye Africa, introduciendo en la película la dialéctica entre lo íntimo y lo colectivo, en el interior de la tensión entre tradición y modernidad. Casado en Francia con una mujer blanca y con hijos mestizos, el personaje del director de cine pretende recuperar temporalmente una relación erótica con una actriz que actuó en una película suya anterior, en la que ella interpretaba a una joven enferma de SIDA. Ella vive aislada, porque la gente cree que realmente está infectada, y le pide que se la lleve con él, que la saque de allí, pero él rechaza esta posibilidad de plano y ella termina suicidándose. Más adelante, durante un casting para la película que pretende realizar, interroga a las mujeres acerca de si les importaría actuar desnudas, ante lo que se escandalizan porque la tradición, la familia y la colectividad no lo tolerarían. En el inicio de la película, Haroun se ha referido a Freud; poco más adelante, sufre la agresión de un individuo al que estaba filmando por la calle, porque le estaba robando su imagen. La película sugiere más que dice, plantea interrogantes más que responderlos. ¿Se pueden disociar cultura y tradición? ¿Cómo mantener el sentimiento y las responsabilidades de la pertenencia a una colectividad una vez que la modernidad ha hecho el elogio del individuo? Y, además, ¿no es la modernidad un producto de la cultura occidental? ¿No vive África bajo una situación poscolonial? ¿No está atada a un vínculo neocolonial con Occidente? ¿No es cierto que los intentos por liberarse de esa tutela han traído guerras, fracasos como el del Chad o el del Congo?

Haroun escucha en la televisión un discurso del capitán Thomas Sankara, sobre el neocoIonialismo, el rechazo de la ayuda exterior y la necesidad de producir, también intelectualmente, para asegurar la independencia real de África. ¿Se trata de un improbable discurso televisado en Chad en 1999, de un video? Como se sabe, Sankara, presidente de Burkina Faso, que estaba en contra de pagar la deuda externa, fue asesinado en 1986. Pero indirectamente, a través de Sankara, aparece el recuerdo de Mandabi (Le mandat, Sembène, 1968), una película que se posiciona abiertamente en contra de la ayuda externa que luego se traduce en deuda ${ }^{5}$.

Poco después, como repasando la distancia entre la utopía pasada y la realidad actual, Haroun recibe una carta de Jean-Pierre Fila quien, desde el Congo, le cuenta que la situación

4 Ver también Lelièvre, 2006: 6: "Realizadores como Abderrahmane Sissako, o Jean-Marie Teno, entre otros, han comenzado a proponer representaciones cinematográficas de destinos individuales que parecen corresponderse con una forma de madurez de prácticas cuyo objetivo será menos responder, didácticamente, a las expectativas de un público partidario de tal o cual causa política, sino, cada vez más, de constituir una mirada subjetiva experimentando su libertad».

5 «Le Mandat es una película que, a pesar de su 'naïveté' ocasional me ha marcado» (Sene, 2010). 
del cine allí es similar a la de Chad: desaparecen los cines, no hay posibilidad de hacer películas sin ayuda exterior, ha llegado la plaga de los videoclubes. Y le manda una cita de Aimé Césaire:

La crisis cultural que atravesamos actualmente puede resumirse así: esta cultura que es la más fuerte en el plano material y tecnológico aplasta todas las culturas más débiles, sobre todo en un mundo en el que las distancias ya no son un obstáculo. Porque las culturas técnicamente más débiles no pueden protegerse a sí mismas. Todas las culturas tienen, entre otras cosas, una base económica, social y política y ninguna de esas culturas puede sobrevivir si no puede guiar su propio destino político.

Es interesante comprobar que esta cita es falsa. No está en el discurso en la Sorbona de 1956, como se dice en la película. ¿Por qué dar una cita falsa? En el conjunto de una película que mezcla realidad y deseo, documental y ficción, una cita falsa se mantiene dentro de la coherencia, pero sin duda hay algo más: si el espectador está interesado, puede también convertirse en lector. En Cultura y colonización - pronunciado pocos años antes del inicio de las independencias africanas- Césaire afirma primero la existencia de una cultura negra, antes de mostrar cómo el colonialismo ha vaciado a los pueblos colonizados de su propia cultura suprimiendo su autodeterminación política. En estas condiciones, la cultura dominada carece de la posibilidad de poder renovarse y transformarse. Nunca podrá darse una cultura mestiza, porque no hay contacto real entre civilizaciones, sino imposición de una, la capitalista, que crea en el interior de las sociedades colonizadas una situación de barbarie, entendida como yuxtaposición desordenada de rasgos culturales distintos. El pueblo colonizado puede volver a encontrar una unidad cultural, que ya nunca podrá ser una simple vuelta al pasado, sólo en situación de libertad y autodeterminación política. En este nuevo escenario, habrá elementos europeos y elementos africanos que buscarán una síntesis:

Estamos actualmente en el caos cultural. Nuestro papel es declarar: liberad al demiurgo que es el único que puede organizar en una nueva síntesis este caos, una síntesis que merecerá el nombre de cultura, una síntesis que será reconciliación y superación de lo antiguo y de lo nuevo. Estamos aquí para decir y para reclamar: dad la palabra a los pueblos. Dejad entrar a los pueblos negros en el gran escenario de la historia (Césaire, 2006: 61).

Como se ve, no hay realmente contradicción entre la supuesta cita que aparece en la película y los postulados de Césaire. Hay sin embargo en la película una transformación: caos cultural por crisis cultural, y dominio colonial por cultura dominante que posee la fuerza tecnológica en un mundo sin distancias. En una película cuyo centro es la relación entre el cine y la realidad, la supuesta cita de Césaire transmitida por un cineasta de un país en guerra a otro en una situación similar se mantiene dentro de lo que es el centro de gravedad argumental. Países que han convertido la guerra en su cultura no pueden producir otra forma de cultura. El problema viene si relacionamos esto con el discurso de Sankara y con su asesinato no aclarado.

Si en este punto el espectador se convierte en lector y va al texto de Césaire, termina yendo al origen del problema, que es el colonialismo, a la necesidad de una liberación real, 
que en el caso del cine está aún por conseguirse. Y a la necesidad de «organizar en una nueva síntesis este caos» para crear una auténtica cultura, imposible en un estado de guerra permanente.

Como en el caso de la tradición, la problemática política ha sido trasladada por Mahamat-Saleh Haroun a un segundo plano, mediante la puesta en abismo, como en las muñecas rusas. Se trata, así, Bye bye Africa de una obra cinematográfica cerrada y completa, al mismo tiempo que abierta, en la medida en la que el espectador acepte el reto de no considerar las referencias extracinematográficas sólo como citas, y acercarse a las obras referenciadas.

\section{UNA FORMA PARTICULAR DE PUESTA EN ABISMO}

Esta estrategia va a continuar, de una manera más refinada, en Abouna y en obras posteriores. En Abouna, dos hermanos son abandonados, junto con su madre, por el padre. Salen en su busca y cruzan la frontera con Camerún sin permiso. Algún tiempo después, creen ver a su padre mirándoles en una película en el cine y deciden robar los rollos de película. La gota colma el vaso, y su madre les envía a una escuela coránica en un lugar lejano para que aprendan a ser responsables. Los métodos son excesivamente duros y el mayor es encadenado tras un intento de fuga. El pequeño morirá por un ataque de asma. El mayor, enamorado de una joven muda, volverá a casa con su novia, tiempo después, para vivir con la madre que, en ese tiempo, había sido internada por problemas psiquiátricos derivados del dolor.

El argumento es muy sencillo, pero la película es enjundiosa. La tensión entre realidad y ficción que se daba en Bye bye Africa ha sido trasladada en su conjunto al lado ficcional. De hecho, comienza con las imágenes de un hombre adulto que se encamina hacia el desierto con una maleta, se vuelve y mira a cámara antes de los créditos iniciales. Una mirada a cámara similar la volveremos a encontrar cuando los niños crean ver a su padre en una película dirigiéndose a ellos, aunque allí inmediatamente sigue la entrada en campo de dos niños que rompen la ilusión. La segunda parte de la película muestra el progresivo distanciamiento del padre por parte del hijo mayor, que encuentra otro centro de interés en una joven, mientras que el pequeño sigue obsesionado por recuperar al padre. De hecho, la gran fotografía que reciben, supuestamente enviada por su padre desde Tánger, que es un rompeolas, adquirirá movimiento ante la mirada del pequeño, cuya mano entrará en campo para acariciar la ausencia.

Como ocurría en Bye bye Africa, la película se cierra sobre sí misma, pero sin dejar de reenviar a un texto, en este caso El principito, de Saint-Exupéry. El padre le leía el libro al hijo menor, y este se quedaba siempre dormido a las primeras líneas. La noche en la que va a morir, porque nadie es capaz de encontrar su espray contra los ataques de asma que padece, le pide a su hermano que le lea el libro entero, prometiendo que esta vez va a escuchar hasta el final. Lo que hay al final de El principito, es un acuerdo entre este y la cobra, para que con su veneno le permita volver a su propio planeta con la flor perdida. Pero eso no lo puede saber el espectador que no conoce la obra de Saint-Exupéry, sino sólo el que acepta el reenvío, y lee o relee El principito desde la película. Una vez aceptado el reto, la muerte del pequeño Amine resulta más problemática: ¿ha perdido voluntariamente el inhalador, del mismo modo que el Principito pactó con la cobra? Y si fuera así, ¿por qué?, ¿intuye o sabe que ha perdido definitivamente al padre? El póster del mar que ante él había cobrado vida, el mar solo, sin una figura humana, parece establecer entre él y su padre una distancia interplanetaria, al tiempo que recuerda al espectador la tragedia de las pateras y los ahogados en su viaje en 
busca de trabajo. No es gratuito pensar esto, ya que el propio Mahamat-Saleh Haroun (Scott, 2003: 90) se encarga de establecer vínculos de complementariedad entre su película y la de su productor —Abderrahmane Sissako-: Heremakono, donde la localidad que vive entre el desierto y el mar es un lugar de paso, a donde a veces se retorna sólo como cuerpo que arrastran las olas. Pero no se trata sólo de eso, que ya sería bastante:

Mediante el juego de la puesta en abismo, tenemos «un cuento dentro de un cuento», dos cuentos con aire de fábula, cuyos protagonistas son niños, dos relatos dominados por la mirada y la visión de un niño. Es decir una visión otra que, en esencia, se opone a la del adulto. Amine y su hermano sufren la arbitrariedad de un mundo que se les escapa, un mundo que los aplasta sin piedad y que no pueden más que asumir. De golpe, lo único que pueden hacer es sobrevivir en un mundo mortífero, construirse una visión, afirmarse. Así alcanzamos el mensaje de El Principito, que no es otro que el del niño desengañado por lo absurdo del mundo de los adultos (Ouédraogo, 2011: 168).

Haroun sigue poniendo en marcha una estrategia interesante, que consiste en cargar de profundidad una obra cinematográfica que se complementaría con otras obras, literarias —como es el caso de El Principito—, o cinematográficas, como Heremakono, de Sissako, o Los cuatrocientos golpes, de Truffaut. En Abouna, el robo de las bobinas de la película en la que han creído ver a su padre, va precedido por la imagen de Amine robando un pequeño cartel publicitario a la puerta del cine, remitiendo así al hurto que hacen los niños en la película de Truffaut, y permitiendo que el espectador —o la memoria cinéfila de la crítica que venga en su ayuda - recuerde otras infancias rotas en un mundo adulto absurdo, otras experiencias de represión y reclusión, otras experiencias de intentos de fuga, de búsqueda de la libertad (Jeffries, 2002).

Podríamos recordar otros carteles que también están presentes en aquel cine: El chico, de Chaplin, Strangers in the Paradise, de Jarmush que contribuyen a enriquecer el sentido de la película. No se trata sólo de citas cinéfilas o de declaraciones de preferencias, sino de establecer vínculos con obras con las que se puede trazar paralelismos temáticos. Como veremos, Haroun volverá a utilizar esta estrategia en Sexe, gombo et beurre salé, y en Un homme qui crie. Resulta entonces extraño que no lo haga en Daratt, que sigue inmediatamente a Abouna. Aunque la película fue financiada por New Crowned Hope para conmemorar el 250 aniversario de Mozart, por encontrar en el guión de Haroun paralelos con La clemenza di Tito. Haroun insiste en que este ya estaba escrito, y que él se limitó a encontrar para la película el ritmo «mozartiano» apropiado, sin insistir en las posibles concomitancias. En esta historia de venganza y perdón, Haroun halla más bien la posibilidad de entender al protagonista como un «Hamlet moderno».

También en este caso la historia es sencilla: Atim es enviado por su abuelo a Ndjamena con el único fin de matar a Nassara quien, en el curso de las guerras civiles que han asolado Chad, asesinó al padre de éste. Atim es incapaz de matar fríamente a alguien a quien no conoce, de modo que empieza a trabajar en la panadería de Nassara. Con el tiempo, Nassara concibe por Atim el afecto por el hijo que nunca tuvo, mientras que Atim lucha consigo mismo ante una situación que le dificulta cumplir la venganza.

Es cierto que no hay en Daratt, como en los casos estudiados y en sus películas posteriores, una obra citada a la que remita directamente. Por el contrario, parece enraizar en 
una serie de películas africanas que tienen como tema básico la rebelión contra los dictados paternos, o las relaciones conflictivas con el padre. Pensemos, por poner sólo unos pocos ejemplos, en Xala, de Sembène, Tilaï, de Idrissa Ouédraogo, en los jóvenes rebeldes de Cissé en El viento, o de un modo aún más explícito, aunque desarrollado de manera mítica en la batalla entre hijo y padre en Yeleen, del mismo autor. Pero si en Yeleen el padre, como un Layo al que se le ha anunciado que su hijo lo destruirá, persigue a este hasta que ambos se aniquilan mutuamente, en Daratt, y frente a tantos ejemplos de conflicto irresuelto o finalizado en tragedia, Haroun opta por una muerte simbólica del padre al mismo tiempo que por una recuperación de la figura paterna. Recordemos el final: Nassara pide a Atim que le permita adoptarlo, y este le lleva hasta la aldea con el pretexto de solicitar la aprobación de la familia. Allí le espera el abuelo, deseoso de saber si Atim ha completado la venganza. Ante el abuelo ciego, que le pide que mate allí mismo a Nassara, Atim disparará al aire.

Según Haroun, quien ironiza diciendo que se trata de un Hamlet que conocía el cine, y que escenifica la muerte del asesino de su padre sin matarlo realmente (De Franceschi, 2007), se trata, sobre todo, de utilizar las posibilidades de una ficción autoconsciente para hacer una propuesta con calado político. La autoconsciencia de la representación no es desplegada de forma tan radical como en Bye bye Africa, ni mediante juegos que apunten a la dimensión simbólica del relato, sino trabajando rigurosamente con una forma de mostrar que rehúye el contracampo —aunque no lo proscribe-, curiosa y paradójicamente, en una película en la que los personajes se observan constantemente.

Es imposible no acordarse de Hamlet —como recordaba el propio Haroun - o del mito de Edipo viendo Daratt. Por si no fuera suficiente con el tema del asesinato del padre, $\mathrm{Ha}-$ roun ha compuesto una secuencia central en la que la joven esposa de Nassara, forzada por la familia a casarse con él, y Atim, parecen entenderse alegremente, hasta que callan por la llegada de Nassara.

Sería interesante volver a la relación de Haroun con Sissako, y la posibilidad de encontrar intertextualidades entre las obras de ambos autores. Chinguitti Films, la productora de Sissako, participó en Daratt. Mientras tanto, Sissako rodaba Bamako, una película en la que se representa un juicio africano al Banco Mundial y al FMI. Sin duda son obras muy diferentes, pero políticamente complementarias, ya que si en una se plantea la reconciliación, en la otra se ataca el problema de la deuda. Deuda y guerra como núcleos de la actual postración de África

Pero, de momento, Daratt es un paréntesis en la estrategia que hemos ido comentando, que consiste en sugerir directamente al espectador, mediante citas y alusiones, el complemento de la obra que, al mismo tiempo, se nos ofrece como un todo acabado.

Terminaré comentando brevemente los dos últimos largometrajes de Haroun. El primero es una obra para televisión, titulada Sexe, gombo et beurre salé; el segundo, Un homme qui crie.

Sexe, gombo et beurre salé es una comedia que se centra en una familia africana que vive en una ciudad francesa. El marido, Malik, ha sido abandonado por su esposa Hortense, bastante más joven que él, que se ha enamorado de un francés blanco, criador de ostras. Incapaz de cuidar a los dos niños pequeños y humillado, Malik intenta que su esposa vuelva con él, sin conseguirlo, mientras la señora Fátima, una vecina del inmueble, está deseosa de conseguir su amor. Para colmo, descubre aterrado que su hijo mayor, que vive fuera de casa, es homosexual, y nunca le dará descendencia. Este, le traerá a casa a una joven africana sin 
trabajo recién llegada al país, que ni siquiera recuerda cómo preparar la comida tradicional a base de okra. La película se cierra después de que algunos de los conflictos se superen con la ayuda de una tía venida de África; el hijo mayor y la joven africana, que está embarazada llegan a un acuerdo, y le anuncian al padre que va a ser abuelo. Un cierre cómicamente en falso, porque la joven le dice en un aparte al «novio» que quizás el niño sea blanco.

La comedia está llena de interés, por mostrar de manera ligera y divertida contradicciones culturales ligadas a la emigración, sin tocar siquiera de soslayo cuestiones como el racismo. Al contrario: muestra los flancos débiles de la aculturación. Y si en el padre encontramos la representación paródica de ese flanco, uno de los dos hijos pequeños nos reserva, también al final de la película, una sorpresa. Siempre con sus cascos en los oídos, como si estuviera escuchando música o pendiente de un videojuego, sabremos en ese momento qué es lo que oye. Se trata de un poema de Birago Diop: Souffles, del que Haroun ha escogido este fragmento:

Ceux qui sont morts ne sont jamais partis,/lls sont dans le sein de la femme,/ Ils sont dans l'enfant qui vagit,/Et dans le tison qui s'enflamme./Les morts ne sont pas sous la terre,/ Ils sont dans le feu qui s'éteint,/Ils sont dans le rocher qui geint,/ Ils sont dans les herbes qui pleurent,/lls sont dans la forêt, ils sont dans la demeure,/Les morts ne sont pas morts./ Ecoute plus souvent/Les choses que les êtres,/La voix du feu s'entend./Endents la voix de l'eau./Ecoute dans le vent/Le buisson en sanglot:/ C'est le souffle des ancêtres ${ }^{6}$ (Diop, 1960).

\section{Como muy bien supo ver Olivier Barlet:}

'Los que se han ido nunca vuelven y cuando regresan, ya no son los mismos', había dicho antes Malik pensando en Hortense, pero hablando de su propio exilio. Este argumento no cesa de rebotar en espiral (Barlet, 2008).

La espiral que nos lleva, si queremos, en abismo. Aunque en este caso, tratándose de un largometraje para la televisión, la cita que se ha introducido es lo suficientemente larga como para que el telespectador no necesite ir a buscar más allá de lo que se le ofrece de manera inmediata, aunque es fácil entrar en Internet y encontrar incluso versiones manuscritas y cantadas del poema, con sólo escribir un verso. ¿Es que el cine y la televisión permiten estrategias similares pero distintas en su exigencia?

Un homme qui crie consigue el Premio del Jurado en la edición de 2010 del Festival de Cannes. El argumento es aparentemente sencillo, como siempre. Adam, antiguo campeón de natación y actualmente encargado de la piscina de un lujoso hotel a cuyas órdenes trabaja su hijo Abdel, se ve degradado por causa de su edad a portero, ascendiendo Abdel a jefe de piscina. Voluntariamente, Adam deja de pagar el dinero que asegura que su hijo no será

6 Ensayo una traducción:

Los que han muerto nunca se han ido,/están en el seno de la mujer,/están en el niño que llora,/ y en el tizón que se enciende./Los muertos no están bajo tierra,/están en el fuego que se apaga/están en la roca que se queja,/ están en las hierbas que Iloran/están en el bosque, están en la morada,/los muertos no están muertos./Escucha más a menudo/a las cosas que a los seres,/la voz del fuego se oye/oyes la voz del agua./Escucha en el viento/el matorral sollozante:/es la respiración de los antepasados. 
reclutado para luchar contra los insurgentes en la guerra civil, y este es enviado al frente. Tras la llegada de la jovencísima amiga embarazada de Abdel, Adam viaja en su sidecar hasta el hospital militar de campaña donde su hijo está gravemente herido para traerlo de vuelta a casa. Por el camino, Abdel muere, y su padre lo entrega al río.

La película remite a través de su título y de una cita final, al libro de Césaire Cahier d'un retour au pays natal, del que reproduzco un fragmento mayor que el que aparece en la película, subrayando en cursiva este último:

Iría a esa tierra mía y le diría: 'Abrázame sin temor... y si sólo sé hablar, hablaré por ti'. Y le diría aún:

'Mi boca será la boca de las desdichas que no tienen boca, mi voz, la libertad de las voces que se desploman en la mazmorra de la desesperación.'

Y regresando me diría a mí mismo:

'Y sobre todo, mi cuerpo y también mi alma, cuidaos de cruzar los brazos en estéril actitud de espectador, pues la vida no es un espectáculo, un mar de dolores no es un proscenio, un hombre que grita no es un oso que baila...'

(Césaire, 1939).

Como decía más arriba, justo cuando llega el fundido a negro final, aparece el fragmento que he subrayado, con la referencia de autor, título y edición. El que un fragmento literario aparezca referenciado de esta manera en una película no es habitual, y merece la pena recabar en ello. Haroun ha utilizado un fragmento del poema rompiendo la frase — frase que sí recupera completa Sissako en La vie sur terre-, de modo que lo que la voz poética se decía a sí misma parece aquí interpelar directamente al espectador. Remitir entonces al conjunto del libro no es ni gratuito ni académico, es hacer justicia y de nuevo, como en ocasiones anteriores, darle la oportunidad al espectador de convertirse también en lector e interpretar a la luz de la obra de Césaire lo que esta película ambientada en un Chad en guerra puede tener de «retorno al país natal».

Esto sucede al final, y tampoco parece gratuito: en el interior de la película, las referencias son otras, sobre todo a El último hombre, de Murnau (1924). No hay citas explícitas, no reenvía directamente, sino que espera la colaboración de la crítica cinéfila o erudita que la saque a la luz, como ocurre en la entrevista con Guillaume Richard (Richard, 2010). Efectivamente, en la película de Murnau nos encontramos con el botones de un hotel lujoso que, por causa de su edad, es degradado a cuidar los servicios, perdiendo el uniforme que, en la sociedad alemana de aquellos tiempos, daba prestigio a quien lo llevaba. Aquí, inversamente, la degradación trae consigo el paso de la camiseta al uniforme que recuerda la época colonial.

El nombre de Adam del protagonista, es decir, el primer hombre, remite a ese último hombre y a su sufrimiento. Aúna en el sufrimiento al europeo y al africano. Y connota una dimensión mítica: Adán es el hombre, el primer hombre. Pero la película también permite establecer conexiones con Daratt. El personaje de Adam es representado por el mismo actor que interpretaba allí a Nassara. Si Nassara quería adoptar al joven que deseaba matarlo, aquí, Adam se desembaraza de un hijo que lo sustituye al frente de la piscina. El pecado de Adán, aquí, no es comer la fruta del árbol del bien y del mal, sino, a un nivel más freudiano -recordemos la alusión a Freud en Bye bye Africa-, negarse a aceptar la natural sustitución de 
los padres por los hijos, negar que envejece. Como un Layo aterrorizado al que un oráculo le hubiera profetizado que su hijo lo acercaría a la muerte. No es la primera vez que una película africana busca una caja de resonancia a través de mitos no africanos o la tragedia griega, baste pensar en Hiènes, de Mambety, con quien abríamos este artículo, en Sissoko —cuya colaboración se agradecía en los títulos de crédito de Bye bye Africa- y su Génesis, o en Le complot d'Aristote, de Bekolo. Pero quizás se trate de la primera vez que, a través de la referencia a Césaire, se aluda explícitamente a la situación poscolonial relacionándola con la intemporalidad del mito.

Si Hyènes, de Mambety, suponía, adaptando a un autor europeo, un hecho excepcional en el cine africano, la obra de Haroun aspira, como diría Césaire, a colaborar en la construcción de una nueva síntesis que, desde la libertad, reorganice el caos cultural heredado del colonialismo y saque África de los márgenes para traerla al centro del mundo. De ahí, el interés por estar en Cannes en competición, y no ya en confrontación?.

\section{BIBLIOGRAFÍA}

ARMES, Roy (2006), African Filmmaking. Nord and South of Sahara, Bloomington, Indiana UP. BARLET, Olivier (1997), «Le régard occidental sur les images d'Afrique», en Africultures. 1-101997, http://www.africultures.com/php/index.php?nav=article\&no=138

- (2000), «Les nouvelles écritures francophones des cinéastes afro-éuropéens», en Cinémas: revue d'études cinématographiques / Cinémas: Journal of Film Studies, vol. 11, n¹, 2000, p. 125.

- (2002), "L'exception africaine», en Africultures, 1 de febrero de 2002. http://www.africultures.com/php/index.php?nav=article\&no $=2059$

- (2008), «Sexe, gombo et beurre salé», en Africultures, 24 de junio de 2008. http://www. africultures.com/php/index.php?nav=article \&no=7683

- (2011), "La colère de Mahamat-Saleh Haroun. Le cinéaste dit adieu à Fespaco», Entrevista con Haroun, en Le Ne GRO POLITAN. Identité et questions nègres, 26 de marzo de 2011.

http://identitenegre.blogspot.com/2011/03/la-colere-de-mahamat-saleh-haroun-le.html

BATUMIKE, Cikuru (1992), «Entrevista con Djibril Diop Mambety», Accesible en http://www. dissidenz.com/film-29071-Hyenes-apropos\#

CÉSAIRE, Aimé (1939), "Cahier d'un retour au pays natal», Revista Volontés, París, 1939, Traducción española de José Luis Rivas en OLLÉ-LAPRUNE: Para leer a Aimé Césaire, México, Fondo de Cultura Económica, pp. 33-76.

(1956), «Culture et colonisation», Présence Africaine, n especial 8-9-10, junio-noviembre de 1956, pp. 190-205, Traducción española en Discurso sobre el colonialismo, Madrid, Akal, pp. 45-75.

DE FRANCESCHI, Leonardo (2007), «L'immagine-tempo. Un'utopia postafricana. Intervista con Mahamat-Saleh Haroun», Cinemafrica. Africa e diaspore nel cinema, Sabato, 26 maggio 2007. Accesible en

http://www.cinemafrica.org/spip.php?article307\&var_recherche=mahamat-saleh

7 El compromiso de Haroun con Chad, como cineasta, le ha hecho implicarse activamente en la rehabilitación de salas cinematográficas. Como consecuencia del éxito de Daratt, el propio gobierno decidió colaborar en la restauración del cine Normandie, la única sala cubierta de Ndjamena. 
DIOP, Birago (1960), «Le souffle des ancêtres», en Leurres et Lueurs, Paris, Présence Africaine. GONZÁLEZ GARCÍA, Fernando (2010), «Diversidad y riqueza del cine africano subsahariano. Reescrituras, transescrituras, intertextualidades», en PÉrEz BowIE, José Antonio (ed.) Reescrituras fílmicas. Nuevos territorios de la adaptación, Salamanca, Universidad de Salamanca, 2010, pp. 209-238.

JEFFRIES, Stuart (2002), "Out of Africa», en The Guardian, Friday 15 November 2002 http://www.guardian.co.uk/culture/2002/nov/15/artsfeatures3.

LELIĖVRE, Samuel (2009), "Histoire, mémoire et légitimation politique dans les cinémas africains», en Revue de I'Université de Moncton, vol. 40, n 1, 2009, p. 6.

OUÉDRAOGO, Amadou (2011) «De la quête du père à l'affirmation de soi: errance initiatique et mise en abyme dans le film Abouna de Mahamat-Saleh Haroun», en OUÉDRAOGO, Jean, Figuration et mémoire dans les cinémas africains, Paris, L'Harmattan, 2011, p. 168.

RICHARD, Guillaume (2010), «Interview de Mahamat-Saleh Haroun pour Un homme qui crie», en UniversCine Belgique, 24 de septiembre de 2010. http://universcinebelgique.wordpress.com/2010/09/24/interview-de-mahamat-saleh-haroun-pour-un-homme-qui-crie/

RUELLE, Catherine (ed.) (2005), Afriques 50. Singularités d'un cinema pluriel, Paris, L'Harmattan. SCOTT, A. O. (2003), «Taking what you need to refresh», En BonETTI, Mahen y REDDY, Prerana (eds.) Through African Eyes. Dialogues whit the Directors, African Film Festival, 2003, pp. 87-92.

SENE, Fatou K, (2010), «Mots croisés avec... - Mahamat-Saleh Haroun, cinéaste tchadien: 'C'est cyniquement que les pouvoirs africains refusent de financer le cinéma'», en Walfadjiri/ L'Aurore. 1 de diciembre de 2010, http://www.walf.sn/culture/suite.php?rub=5\&id art $=69194$

SERVAIS, Jean, DıOP, Baba y TAPSOBA, Clément (1992), "A Cannes en confrontation, pas en compétition», Africultures, n², troisiéme trimestre 1992, pp. 2-6.

SOUVANNAVONG, Kèoprashit (2010), "Un homme qui crie, premier film tchadien en course pour la Palme d'or», en rfi, 16 de mayo de 2010, http://www.rfi.fr/contenu/20100516homme-crie-premier-film-tchadien-course-palme-or

UKADIKE, N. Frank (1999), "The Hyena's Last Laugh [interview with Djibril Diop Mambety]», Transition 78, vol.8, no. 2, 1999, pp. 136-53. 